\title{
A Comparative Study of National Human Resource Development Plan Implementation Systems in Korea, the United States, and J apan
}

\author{
Shin Bok Kim,* Young Hwan Lee, ** and Do Young Jung***
}

\begin{abstract}
This article provides a comparative analysis of National Human Resource Development (NHRD) Plan implementation in Korea, the United States, and Japan. This study demonstrates that Korea is in a position very different from America's and Japan's with their unified NHRD Plans. First, while Korea provides systematic legal support in order to realize the NHRD Plan, especially with the enactment of the Human Resource Development Act, Japan and the United States lack such a legal basis. Second, from the perspective of systems to promote cooperation and participation, Korea has a key minister in charge of policy enforcement and an interagency process. Third, to win funding and support from policy-makers, Korea, the United States, and Japan fully recognize the importance of NHRD Plans and make their best efforts to win budget and support from top decision-makers. Fourth, in terms of the substantiality of annual enforcement plans, Korea has rather abstract criteria and less consistency in implementation. Fifth, as far as active publicity efforts are concerned, Korea lags behind Japan and the United States.
\end{abstract}

Keywords: National Human Resource Development (NHRD) Plan, Strategic Plan, Policy Implementation, Comparative Study

\footnotetext{
* Shin-Bok Kim (Ph.D., University of Pittsburgh) is a professor of the Graduate School of Public Administration, Seoul National University. He is also a vice president of Seoul National University. His research interests include Human Resource Management, Planning Theory.Email: sbkim1@snu.ac.kr.

** Young Hwan Lee (Ph.D., University of Seoul National University) is a Post doctoral fellow of the Graduate School of Public Administration, Seoul National University. His research interests include Human Resource Management, Public Management Information System. Email: smarthwan@yahoo.co.kr.

*** Do Young Jung is a Master of the Graduate School of Public Administration, Seoul National University. His research interests include Human Resource Management, Policy Implementation Theory. Email: humoo21@snu.ac.kr.
}

Manuscript received December 2008; out for review December 2008; review completed January 2009; accepted February 2009.

The Korean Journal of Policy Studies, Vol. 23, No. 2, 171-188 (2009)

(C) 2009 by the GSPA, Seoul National University 


\section{INTRODUCTION}

The era has already dawned in which quality of human resources has become a key factor in determining a nation's future. Many people agree that improving not only individuals' skills but also management practices and the entire human resources system is critical in determining a nation's long-term competitiveness and prosperity. Countries around the world have made efforts to effectively implement human resource development policies.

Korea understood the importance of human capital long ago and can serve as a good example to other countries of a way to use effective human resources practices to develop into a top-notch economy. However, the consensus is that even though the socalled knowledge-based society has already arrived, bringing the importance of human resources and knowledge into the spotlight, the Korean government has taken disappointing measures thus far. Many experts say that the Korean government neither takes this issue seriously nor responds to it systematically.

With such criticism in mind, this paper compares the ways in which Korea, the United States, and Japan implement NHRD plans, and draws implications for Korea's future policies in order to build an effective plan for fostering human resources. It focuses on the process of implementation, because this issue has not been much studied. Not only policy planning and evaluation but also policy implementation, and issues affecting its success and timeliness, are important to help ensure the better implementation of future national human resource development policies.

\section{THEORETICAL BACKGROUND}

\section{Factors Affecting Implementation of Policy}

Many studies discuss the elements that affect policy implementation. For example, Gunn (1978) suggests ten preconditions for successful policy implementation, including the external environment, time and other resources, implementation plans, and causal links. Sabatier and Mazmanian (1983) argue that there are three influential factors for the effective implementation of policy plans: the tractability of the problem, the degree to which implementation is cohesively structured and nonlegislative variables. The tractability of the problem can be measured by (1) various technical theories and the possibility of adopting technology, (2) the diversity of the behavior of the targeted groups, (3) the ratio of the targeted groups to the general population, and (4) the degree of required behavioral change. The level to which laws and regulations cohesively structure 
the implementation process can be measured by (1) clear and coherent objectives, (2) the incorporation of proper causal theories, (3) financial resources, (4) the hierarchical integration of executive bodies, (5) the decision-making rules of executive bodies; (6) the recruitment of executive agents, and (7) the accessibility of people outside the executive bodies. Lastly, nonlegislative variables affecting implementation are (1) socioeconomic conditions and technology, (2) media attention to the issue, (3) public support, (4) the attitudes and resources of client groups, (5) support from related supervising bodies, and (6) the commitment and leadership skills of the officials in charge. Sabatier and Mazmanian's analysis considerably overlaps with Gunn's. This paper uses five criteria drawn from previous studies of factors affecting policy implementation:

1. legal and institutional environments

2. effective participation and cooperation systems

3. efforts to gain funding and support from policy-makers

4. effectiveness of annual enforcement plans

5. efforts to gain support from related groups

The framework of the study and the specific issues it investigated are presented in table 1.

Table 1. Analysis of the Implementation of National Human Resource Development Plans

\begin{tabular}{|c|c|c|}
\hline Key factors & Sub-factors & Analytical focus \\
\hline $\begin{array}{l}\text { Legal and institutional } \\
\text { environment }\end{array}$ & $\begin{array}{l}\text { - Legal basis for implementation } \\
\text { - Institutional basis for } \\
\text { implementation }\end{array}$ & $\begin{array}{l}\text { - Legal support for implementation } \\
\text { - Related institutional organizations } \\
\text { and mechanisms }\end{array}$ \\
\hline $\begin{array}{l}\text { Participation and cooperation } \\
\text { for implementation }\end{array}$ & $\begin{array}{l}\text { - Participation structure of the } \\
\text { policy personnel concerned } \\
\text { - Functional relations of the } \\
\text { policy personnel concerned }\end{array}$ & $\begin{array}{l}\text { - Existence of opportunities for } \\
\text { participation } \\
\text { - Effective partnerships among } \\
\text { stakeholders }\end{array}$ \\
\hline $\begin{array}{l}\text { Efforts to secure support from } \\
\text { the persons responsible for } \\
\text { budget and policy }\end{array}$ & $\begin{array}{l}\text { - Efforts of the government } \\
\text { agencies concerned } \\
\text { - Efforts to secure support from } \\
\text { policy-makers }\end{array}$ & $\begin{array}{l}\text { Degree to which budgets are } \\
\text { secured by related government } \\
\text { organizations } \\
\text { - Efforts of the officials in charge to } \\
\text { win support }\end{array}$ \\
\hline $\begin{array}{l}\text { Substantiality of the annual } \\
\text { enforcement plan }\end{array}$ & $\begin{array}{l}\text { - Preciseness of the plan } \\
\text { - Consistency of the plan } \\
\text { - Desirability of the plan }\end{array}$ & $\begin{array}{l}\text { - Clear specification of performance } \\
\text { standards and schedules } \\
\text { - Consistency between strategic } \\
\text { plans and annual plans } \\
\text { - Degree of reflection from the } \\
\text { people for work }\end{array}$ \\
\hline $\begin{array}{l}\text { Support from and compliance } \\
\text { by target groups }\end{array}$ & $\begin{array}{l}\text { - Efforts to secure support for } \\
\text { policy implementation } \\
\text { - Efforts to obtain compliance } \\
\text { to policy implementation }\end{array}$ & $\begin{array}{l}\text { - Various promotional efforts to } \\
\text { win policy support } \\
\text { - Whether or not to hold meetings } \\
\text { to collect various opinions to } \\
\text { secure compliance }\end{array}$ \\
\hline
\end{tabular}




\section{OVERVIEW OF NATIONAL HUMAN RESOURCE DEVELOPMENT PLANNING}

\section{Korea}

According to the Basic Act for Human Resource Development and its implementing ordinances, enacted in 2002 and in force today, the Korean government must establish a master plan for human resource development every five years. According to this master plan, all of the heads of central government agencies must formulate and implement annual plans.

Korea's national plan requires action plans to clearly specify both sub-plans and related plans and show the scope of the work and the quantity of the materials in detail. Plans must also specify the policy-driving subject, the budget, plans to secure financing, and investment plans, so as to ensure stable resource mobilization.

During or after the process of policy materialization, examination, and evaluation to confirm whether policies have been faithfully conducted, what is written in the reference guide for the original plan must be followed, and the performed activities must be corrected if necessary. There are both monitoring processes and evaluation processes. Monitoring measures the output of the activities - in other words, the completion of construction work on a reservoir, the number of cured elders, the number of consulted school boys and girls. Evaluation measures whether the activities were conducted according to the procedures specified in the policy guide.

The NHRD Plan also contains the following factors. The Minister of Education, Science, and Technology annually evaluates activity results under the master and action plans, based on Articles 8.1 and 8.2 of the law on national human resource development. This is systematically and effectively to drive forward human resources policy being conducted under each government organization, thus evaluating the results of the master and annual plans, which are established and implemented every five years. Reports must also be made to both the Human Resource Development Committee and the government. However, this contains the consulting activities to promote human resource development plans or related work as well as evaluation to set up the order of precedence.

\section{United States}

The U.S. federal government does not have a single organization in charge of human resource development policy, but promotes human resource development through a decentralized system. For instance, the Department of Education is in charge 
of vocational education for adults, the Department of Labor is in charge of employment and job training, and the Department of Energy supports human resource development in science and technology. While the federal human resource development policy focuses on certain classes or groups such as the economically vulnerable, state governments generally focus on local residents. In particular, in the case of employment training, which is one of many forms of human resource development, state governments play a greater role than the federal government and also provide more financial support.

U.S. human resource development is carried out at three levels: federal, state, and local. Each level of government establishes, implements, and evaluates its own human resource development plan according to the federal or state constitution or other relevant laws and regulations. But they all share a common philosophy, which is that each organization has the liberty to operate autonomously in the education market within the legal boundaries and that healthy competition helps to maximize educational effects. Consequently, government plans at each level are intended not to supervise or to control but to support the autonomous efforts of educational organizations and to promote competition as much as possible.

The United States focuses on implementation outcomes and develops policy based on the Government Performance and Result Act (GPRA), which means that it puts more weight on policy implementation results than on the policy implementation process or monitoring. In addition, it emphasizes the responsibility and liability for policy implementation and, at the same time, is strengthening the flexibility required for policy implementation. In other words, this Act is as applicable to the implementation of human resource development plans as it is to other governmental activities, and the federal government conducts a comprehensive performance accountability system to maximize the effects of federal aid to state and local governments.

\section{Japan}

The national human resource development plan in Japan started when the government accepted a budget request for implementing national primary guide and education reform-related acts including the 21st Century Newly Developed Education Plan (2001) and the Human Resource Strategy Vision (2002). The national human resource development plan is conducted primarily as a tool of education reform and emphasizes cooperation rather than bureaucratic control. Another characteristic is that Japan's reform plan for lifelong education is intended to be uniquely Japanese, rather than following Western methods.

The Educational Reform Plan for the 21st Century (2001) is the foundation for national human resource development policy in Japan. It includes projects to encour- 
age young people to study science and technology, school and community volunteer work plans, plans to support the domestic and local lives of men and women, plans to improve colleges, student exchange programs in advanced fields, and on-the-job career advancement programs. The Human Resources Strategy Vision 2002 has six goals: (1) improve study skills; (2) improve human relations; (3) bring up the best brains and versatile abilities; (4) implement reforms to advance the education system into the information era; (5) stimulate and promote accomplishment; and (6) foster Japanese people in the new era.

To promote these reform plans, the Diet enacted six educational reform laws during 2001 and 2002 and also secured budgetary support for these plans. The key contents of this legislations are as follows: (1) the consolidation and incorporation of national universities and the abolition or conversion of short-period colleges (April 2002); (2) national universities' autonomous decisions over staff unions (April 22, 2001); (3) sufficient reflection of school masters' views in personnel management (June 29, 2001); (4) approval of an advanced placement system for students with superior scores in high schools, colleges, and graduate schools (June 29, 2001); (5) the approval of experiential activities such as volunteering, social activities, and reading as educational activities (June 29, 2001); and (6) the establishment of the Children's Dream fund (April 4, 2001)

Japan has not created a comprehensive monitoring and evaluation system for human resource development policy; instead, each ministry or organization is authorized to evaluate the effectiveness of its own policy implementation. Representative evaluation examples of human resource development are: (1) surveys conducted every three years to investigate basic facts about social education; and (2) solidarity and consolidation surveys to study established policies for research development by the National Education Institute and fostering human resources.

In particular, Japan makes it clear that policy objectives, policy priorities, and performance outcome should be specified to help its citizens understand the national human resource development plan and to facilitate monitoring systems by citizens and further encourages executive agencies to use measurable expressions.

\section{COMPARATIVE ANALYSIS}

\section{Legal Conditions}

The legal basis for the NHRD plan in Korea is the Human Resource Development Basic Law, and the central government must be the developer of such plans. ${ }^{1}$ The 
Minister of Education, Science, and Technology is required to craft a basic plan after putting together a draft and deliberating on it in the Human Development Council, the results of which must be reported to Cabinet meetings and to the heads of local governments as well as central government agencies. ${ }^{2}$

The relationship between a basic plan and an implementation plan in NHRD can be specified as follows. Article 5 and Clause 3 of the Human Resource Development Basic Law stipulate that an annual implementation plan must be established based on a basic plan and include the direction and goals of the year's HRD policy, key strategy and top priorities for target performance, financing and investment methods, and responsible divisions and agencies.

The United States has the GPRA of 1993, based on which each federal agency is required to create a five-year strategic human development plan. Furthermore, the Workforce Investment Act explores ways to combine HRD plans and real employment, which is under implementation. Thus, the United States links together human resources and vocational training, thereby seeking to enhance workforce capacity and national competitiveness. However, these legal bases are primarily aimed at increasing the efficiency of the funds invested for this purpose, while limited in their ability to serve as a national-level legal framework for the management of HRD.

In Japan, laws related to HRD include the Education Basic Law-which, since its enactment in 1947, has never been revised, thus making it largely irrelevant to the NHRD plan. ${ }^{3}$ A second related law is the Workforce Development and Promotion Law. This is a full revision of the earlier Vocational Training Law, intended to respond to rapid changes in economic and social environments and promoting the development and improvement of job capacity throughout a worker's entire career (Kang, Lee, \& $\operatorname{Kim} 2005)$.

NHRD plans are giant projects that by nature require an immense amount of funding and manpower and the involvement of several agencies and institutions. In order for such a plan to be successfully implemented, it requires first and foremost an adequate legal basis, which means that manpower, budget, and institutions must be integrated. How the three countries that are the focus of this study meet this standard is discussed below.

First, in Korea, before the Human Resource Development Basic Law was enacted in 2002, an implementation plan had not gone beyond an outline of abstract goals, visions, strategies, and policy priorities. However, since 2003, implementation plans

1. Article 5, Clause 1, Human Resource Development Basic Law.

2. Article 2, Enforcement Rules of the Human Resource Development Basic Law.

3. The Education Basic Law was revised on December 15, 2006. 
have been drafted based on HRD plans, thus allowing them to receive advice from committees of experts on a variety of key challenges including the decentralization of national power and balanced land development. Furthermore, sharing evaluation results, establishing a policy partnership network among relevant agencies and institutions, and clarifying policy priorities have all contributed to the enhancement of efficiency and timeliness of implementation. In other words, compared to the past, Korea has witnessed a significant improvement of its legal foundation for national resource development plans.

In the case of the United States, five-year HRD plans have been implemented since 1993 in accordance with the GPRA. However, because of the U.S. federal system, each state has a bigger role to play, and there is no national-level law or agency governing the management of human resources. The current legal framework provides only minimum central control and support and therefore can be viewed as lacking the ability to implement huge projects such as NHRD plans successfully and consistently.

In Japan, there are two laws related to NHRD plans: the Job Capacity Promotion Law and the Employment Insurance Law. Because these two laws mostly have to do with employment and labor, however, they are believed to be insufficient to encompass both the development and implementation of HRD plans on a national scale. Besides these laws, provincial ordinances, which are revisions of education enforcement rules, also serve as a legal basis for NHRD plans but are limited in validity because they are not laws. In conclusion, Japan does not have a solid legal foundation for implementing NHRD plans, which require a large budget and involvement by several national institutions.

\section{Institutional Conditions}

In 2001, the Korean Ministry of Education, Science, and Technology set the direction of a basic plan for long-term NHRD, for which ten policy priorities were selected, with one of them being the construction of infrastructure aimed at enhancing the efficiency of HRD plans. The initiatives included in this category are: (1) to establish laws and institutions to promote HRD; (2) to build dissemination system for HRD-related information; (3) to set up a network of government-affiliated research centers; and (4) to develop a measurement index for HRD. Out of these, the need for laws and institutions, as explained before, has been met to a large extent, and an HRD policy was also developed and is in current use. Nevertheless, the establishment and use of an information dissemination system related to HRD is still in its infancy. Although information is collected and managed by government agencies and research institutions, it is not sophisticated enough and is largely left unattended in information warehouses or 
devices without being classified, managed, and leveraged properly.

In the United States, there is no single government agency responsible for developing and implementing NHRD plans, but instead several agencies that deal with their own plans and policies. For example, the Department of Education handles the overall education system; the Department of Labor presides over employment security and training; the Department of Commerce offers the National Technical Information Services; the Department of Health and Welfare provides preschool education through the Head Start program; and the Department of Energy supports HRD in science and technology.

In Japan, in 2001, the government organization was downsized and divided into two- the Ministry of Education, Culture, Sports, Science, and Technology and the Ministry of Health, Labor, and Welfare. This has reportedly resulted in the fragmentation of the HRD system. However, Japan is still endeavoring to make the system a success, and it has tied NHRD plans to financial and economic restructuring. The country is also trying to ensure transparency in its educational administrative system through deregulation and decentralization of education and information sharing. Furthermore, it is implementing a job capacity development system to ensure employment security and employment expansion that should accompany changes in the industrial structure, examples of which include streamlining the white-collar training system, expanding the business career system, career analysis and job counseling services, the advancement of talented individuals, and the nurturing of highly skilled laborers.

The three countries' institutional conditions needed to implement HRD plans can be compared in the following manner. First, while Korea has accomplished a great deal in its efforts to establish institutions for this purpose, there is some room for further improvement. The most important problem that needs to be resolved is the lack of the information creation, utilization, and sharing required to successfully implementing NHRD plan.

A federal system by nature, the United States federal and state governments are closely interwoven, with human development implementation institutions, education and training information system, and national information infrastructure available to complement the implementation of human development plans. Considering its federal system, the United States has a very good though imperfect institutional infrastructure.

The most extraordinary thing about Japan is the fact that it is implementing national human development plans in conjunction with various other social institutions. However, the process lacks a central institutional pillar that effectively supports the implementation of the plans, and responsible departments and agencies are fragmented, thus putting constraints on the effective and consistent implementation of NHRD plans. 


\section{Participation and Cooperation}

\section{Participatory Structures}

The most desirable participatory structure in the policy process is that which allows stakeholders to fully express their opinions and to implement their ideas. However, too much participation can impede the efficient implementation of a plan, and thus it is extremely important to determine a participatory structure that can ensure both democratic participation and efficient implementation.

In this regard, this study reviewed whether all stakeholders are guaranteed enough opportunities to participate, and found that there is a noticeable gap from country to country. In Korea, the Ministry of Education, Science, and Technology plays a central role in creating various partnership bodies responsible for formulating and implementing national human development plans. As evidenced in several conferences and evaluation groups, the country has one of the most advanced participatory systems in the world, which combines expert sessions, policy discussions, workshops, and seminars to ensure the collection of diverse opinions and participation by all stakeholders.

The United States does not have a central organization that handles the matter, thus leaving different agencies and institutions to manage their respective operations, so that state and local governments participate more actively than the federal government. Japan often experiences conflicts among departments and agencies because it lacks clear regulations in this area, but it is nevertheless believed to possess a strong participatory structure that allows stakeholders from various social sectors to participate.

\section{Inter-Agency Cooperation}

In Korea, as many as 224 human development-related tasks are scattered across a web of 28 government ministries, agencies, and administrations. It is difficult to reach agreement and achieve voluntary cooperation among all these institutions, since each is concerned to promote its own interests. Fortunately, the new position of Vice Prime Minister of Education, Science, and Technology has been created to coordinate and oversee the process. Minister of Education

The U.S. federal government has little influence over the establishment of pragmatic partnerships and plays a minimal role in this regard. All of the institutions charged with implementing NHRD plans are given their share of power and rarely interfere with one another's jobs because there is no single central organization responsible for supervising affairs associated with national human development plans. It is therefore believed that little cooperation and coordination of any real meaning exists among U.S. federal agencies. Nevertheless, a smooth and effective cooperative system was found to be in place between federal and state governments, especially 
with regard to budget and performance achievement.

Because Japan has tied the implementation of national human development plans to other financial and economic restructuring, the establishment of a cooperative network among government agencies and social and civil organizations is essential. Consequently, the nation has put a partnership and cooperation relationship in place among existing agencies by streamlining the government structure, with the Cabinet Office charged with settling conflicts that occur between agencies and institutions.

\section{Efforts to Secure Funding}

The present study compares and analyzes efforts by different agencies to acquire funding. In the case of Korea, when it developed the first package of NHRD plan, its budget was only 12.8 percent of the entire education budget (2.8786 trillion KRW); this increased to $13.6 \%$ in the second NHRD plan package. The increase resulted from an effort to make the departments responsible for setting budgets understand the importance of these plans, and to these departments' own vigorous efforts to secure funding in Cabinet and parliamentary budgeting sessions.

Every year, in the State of the Union address, the United States president emphasizes the importance of NHRD plans, specifying the exact numbers needed. This represents a strong effort on the part of the administration to acquire the necessary budget. Likewise, Japan stresses the importance of national human development plans from top down, with the prime minister endeavoring to secure the necessary funding to ensure the successful implementation of NHRD plans. As a result, currently, 6.322 yen, or 13.28 percent of the total budget, is invested in these plans. Recently, however, nearly all programs related to national human development plans under the Ministry of Education, Culture, Sports, Science, and Technology experienced budget reductions. This is in contrast with Korea and the United States, where the related budget is increasing, and the phenomenon can also be viewed as evidence of little efforts by related agencies to secure the budget.

\section{Efforts to Secure Support from Policy-Makers}

Korea is doing its utmost to convince officials, at Cabinet meetings and reporting sessions by government departments and ministries, that a solution to many current problems is the development of human resources. It is also trying very actively to win the support of the top policy-maker, suggesting quite often that national human resource meetings be presided over by the president himself.

In the United States, where the role of a governor or local official is important 
given the nature of the federal system, institutions involved in HRD are letting-policy makers know that citizens are keenly interested in HRD plans. In addition, efforts are being made to win the support and interest of members of the Senate and the House of Representatives, who have the ultimate authority to make policy decisions and to approve budget plans.

In Japan, which has a parliamentary system, the government is less stable than that of Korea or the United States. Consequently, in order for NHRD plans to be implemented in a stable and consistent manner even after a power transition, efforts are made to convince the prime minister and other members of parliament that the development of human resources is the only solution to many of the problems facing the nation - such as population aging, economic recession, dwindling fertility rates, and declining academic achievements. In addition, it promotes the issue by issuing government reports and other documents to ensure that NHRD remains on the agenda. However, as seen in recent cuts to the budget set aside for national human development plans, the prime minister and parliament appear to be interested more in the military, politics, and the economy than in education, thus undercutting all of the previously described efforts.

\section{Integrity of Implementation Plans}

\section{Clarity}

Of the three countries, Korea is substantially behind in terms of the clarity of its NHRD plan. The goals are largely vague and without clear performance metrics. Another problem is the lack of a detailed schedule for completion. These problems lead in turn to another set of problems that arise in the process of performance evaluation. Unlike Korea, the United States and Japan have completely overlooked the vagueness inherent in national human development plans, thereby creating a problem: They are attempting to quantify the performance of human resources, which is difficult to measure numerically.

\section{Consistency}

When it comes to policy implementation, both spatial and temporal consistency between a higher-level plan and a detailed yearly plan has a great impact on the plans' success of implementation. In this respect, Korea's yearly plans lack an overriding tone that encompasses the entire plans while including many tasks that are unfeasible, thus making it less consistent than it should be.

The United States maintains a relatively high level of consistency thanks to the GPRA. In Japan, though there is high likelihood that plans lack temporal consistency, 
due to frequent changes of power under the parliamentary system, the government nevertheless endeavors to enhance consistency by producing long-term plans and securing the budget in advance to ensure their implementation.

\section{Hopefulness}

Plans that are sufficiently hopeful are those that reflect the hopes of citizens. Because it plays a very important role in ensuring the successful and effective implementation of NHRD plans, this characteristic is one of the most important criteria that determine whether an implementation system is working or not.

Korea reflects both experts' opinions and public expectations in the implementation of the plans by building policy networks for different tasks. For example, the first package of NHRD plan included the development of skills for stay-at-home mothers and their participation in economic activities, special education and job-search assistance for the disabled, utilization of the senior workforce, and employment support for highly educated women. All of this was a part of the effort to acknowledge Korea's social issues in the human development plan.

Meanwhile, the United States began to set the baseline in 2002, a goal to be attained, and roles and opportunities for expressing opinions for each target group (students, teachers, parents, and schools) associated with national human development plans were clearly defined, thus enabling policies full of hope to be implemented. In addition, various human development programs are being implemented for issues such as educational discrimination among races, the linking of training to employment, and declining academic achievement, which the public wishes to be improved.

In the case of Japan, a variety of advisory bodies are being utilized to ensure that the plans are feasible and supported by the public. One example is the 21 st Century New Education Plan, which utilizes diverse channels and approaches to enhance the hopefulness of the implementation. In particular, the basic plans designed to address long-term challenges are based on advice from the Central Education Council, Lifetime Education Council, and Education Process Council, thereby making the plans more feasible and hopeful.

\section{Efforts to Win Support and Compliance from Target Groups}

In order to win compliance and support from the groups related to a particular policy or the general public, it is imperative to raise awareness of the policy among those groups and citizens. However, in Korea, it is difficult to obtain information on the implementation of national human development plans from the homepage of the Ministry of Education, Science, and Technology, which is a key institution in HRD. More- 
over, only a few people know that the second round of national human development plans are already under way, which means that not enough effort has been made either to promote the plans or to win people's support for them.

The United States is running a regional program designed to win the people's support. The most representative activity is after-school programs aimed at reducing juvenile delinquency and crimes associated with violence and drug abuse, reducing absenteeism, and improving school grades. A cooperative relationship is maintained among schools, civic groups, religious groups, and local economic organizations in the process of running these programs, and it helps to enhance the quality of the programs, not to mention raising the funds needed for program operation. Furthermore, because the public benefits from these policies and programs, the process naturally translates into support for the education policies that are at issue.

In Japan, where there is but slight difference between policies-depending on the policy decision and implementation as called for by the educational reality and social demands - the Minister of Education, Culture, Sports, Science, and Technology usually seeks advice from the Central Education Council, which in turn convenes a special council meeting or a national hearing, if needed, to gather the people's opinions and, at the same time, to encourage the people to comply with the policies. For educational issues that are of high interest to the public yet sharply divide public opinion, this type of a consensus-building mechanism is activated to win the support of the public, which allows the policies to be implemented successfully. They also issue an education white paper to win public support. First published in 1988, the white paper is very comprehensive, as it covers a variety of topics ranging from education and academic trends to sports and culture. Since 1999, it has outlined the details of national human development plans and educational reform to inform the people and to win support for the implementation of these plans.

\section{CONCLUSION}

\section{Summary of Research Results}

The present study has examined the legal and institutional conditions under which NHRD plans are made, implementation-related participatory structures and partnerships, funding efforts, efforts to win policy-makers' support, the integrity of the yearly implementation plans, and efforts to win target groups' support and conformity, against all of which the processes of implementing NHRD plans in Korea, the United States, and Japan have been reviewed and compared. The differences among the three 
countries are summarized below.

In terms of legal and institutional conditions, Korea's Human Resource Development Basic Law plays a central role in providing the legal basis for the implementation of the policy, while Japan and the United States lack a similar legal basis for their plans. The United States was found to be equipped with a good institutional infrastructure, but Korea does not possess a strong institutional system that offers information and data as needed, even though it has various policy commissions and expert groups, and Japan faces a similar situation.

Another key issue is that of partnership systems and participatory structures. Korea has the Ministry of Education, Science, and Technology, responsible for implementing policies and coordinating different positions and interests of diverse government ministries and departments, but this fails to some extent because these bodies continue to pursue their own interests. Nevertheless, many of the stakeholders are provided with opportunities to participate through various participatory structures. Meanwhile, the United States does not have a single key agency holding several sub-departments together; instead, each department and institution is responsible for developing and implementing its own national human development plan. In particular, given the nature of the federal system, state and local governments have a very important role to play. In Japan, a wide array of government agencies and social forces are guaranteed chances to be involved in implementing national human development plans, with the Cabinet Office under the prime minister charged with the job of coordinating various government departments to ensure efficient collaboration among them.

When it comes to budget funding and winning support from policy-makers, the three nations have much in common. They all recognize the importance of national human development plans and seek to secure as much funding as possible and to win the support of top policy-makers in this endeavor. In the United States in particular, where lobbying directed at the Congress is legal, many institutions were found to be working hard to persuade members of Congress who play a critical role throughout the process of making policy decisions, implementing those policies, and approving budgets. Japan shows a similar tendency. However, there are differences as well. Korea and the United States lay the foundation for the stable implementation of national human development plans by securing sufficient funding, while Japan was found to be more preoccupied with matters of the military, politics, and diplomacy than with those of education, and as a result, the budget for various national human development programs is shrinking.

Another issue is how well written the plans in terms of their consistency, hopefulness, and clarity. In terms of clarity, the United States defines the objectives and goals of the policies and programs to be implemented every year. Considering that the per- 
formance of a national human development plan is inherently abstract in itself, however, some standards were unreasonably quantified. In stark contrast to the United States, Korea has not defined the goals and performance metrics with which to measure the end results, and many of its goals and related requirements remain vague and abstract. Review of the 21st New Education Plan of Japan revealed that Japan stood halfway between Korea and the United States. In terms of the hopefulness of the plans, all three countries were found to provide enough opportunities to the general public for expressing their opinions. In terms of the consistency of the plans, Korea was behind other countries, because its higher-level and lower-level plans did not share common goals and were, at times, not implemented at all. On the other hand, the United States, through its Strategic Plans (U.S. Department of Education 2002), and Japan, by formulating long-term plans to overcome the chronic problem of frequent power changes associated with its government system, ensure a high level of consistency; both countries endeavor to implement the plans in a stable manner.

Table 2. Comparison of Korea, the United States, and Japan in implementation of NHRD plans

\begin{tabular}{|c|c|c|c|}
\hline & Korea & United States & Japan \\
\hline Legal basis for implementation & Sufficient & Average & Insufficient \\
\hline Institutional basis for implementation & Insufficient & Average & Insufficient \\
\hline Opportunities for stakeholders to participate & Sufficient & Average & Sufficient \\
\hline Effective partnership among stakeholders & Ineffective & Average & $\begin{array}{l}\text { Somewhat } \\
\text { effective }\end{array}$ \\
\hline Agencies' efforts to secure funding & Sufficient & Sufficient & Insufficient \\
\hline Efforts to win top policy-makers' support & Sufficient & Sufficient & Insufficient \\
\hline $\begin{array}{l}\text { Clearly defined goals and timing for } \\
\text { implementing plans }\end{array}$ & Unclear & Clear & Relatively clear \\
\hline $\begin{array}{l}\text { Consistency between top- and bottom-level plans } \\
\text { and temporal consistency between the plans }\end{array}$ & Low & High & High \\
\hline Reflecting citizens' expectations & Sufficient & Sufficient & Sufficient \\
\hline Securing support for implementing policies & Insufficient & Sufficient & Sufficient \\
\hline Securing the compliance of target groups & Insufficient & Sufficient & Sufficient \\
\hline
\end{tabular}

Despite slight differences, all three countries are making strenuous efforts to put a system in place that will reach out to related stakeholders and are conducting various activities to promote the plans and gain the support and interest of target groups. In terms of the aggressiveness of such promotional efforts, however, Korea was behind 
the two other nations. The United States clearly defines the goals and objectives of its programs and policies by year and also has a long-term perspective in planning budget expenditures, which helps to ensure the consistency of its policies. Korea does not have goals clearly defined for some items, thereby leaving them largely vague and equivocal. Japan stood somewhere between Korea and the United States. The results of the analysis are captured in table 2.

\section{Policy Implications and the Limitations of the Present Study}

The present study yielded quite a few implications for the HRD policy of Korea.

First of all, it is necessary to ponder how national human development plans, which require an enormous amount of funding and time, are meeting expectations through their implementation. To this end, a comprehensive system for national human development plans must be put in place that will help systematically to manage, oversee, and evaluate the plans of different government departments.

In addition, for accurate evaluation of how well the plans are implemented, clear goals, evaluation criteria, and performance metrics must be defined at the time that the basic plans and implementation plans are established. Furthermore, some efforts must be made to conduct interim evaluation of the plans, to develop linkage plans to tie all the related plans together, and to build a system to oversee, to coordinate overall plans, and to improve the efficiency of financial investment.

Despite all these implications, the present study has some limitations as well. More than anything else, compared to Korea, it did not have enough data on the United States and Japan. All three countries focused on implementing policies as successfully as possible, and thus there was relatively little data on policy implementation as opposed to policy formulation and evaluation. In particular, because the United States lacks a central body responsible for HRD plans, it was not easy to find relevant data. Instead, in the United States, all of the policies on the national level are developed, implemented, and evaluated within the broad framework of the strategic plan, and national human development planning and implementation, which are a part of this broad arrangement, are carried out by each government department, thereby making it difficult to conduct analysis systematically in line with the intention of the present study. Likewise, in the case of Japan, though there is a relatively large amount of data available on how national human development plans are formulated and evaluated, it was difficult to find detailed documents on how those plans are implemented. In addition, Japan lacks a separate institution that is responsible exclusively for handling HRD plans, thus leaving the job of analyzing the concept behind HRD plans extremely challenging. Unlike Korea and the United States, both of which have a presidential 
system, Japan's government is based on a parliamentary system, which affects the process of implementing policies. This was also a limiting factor for the comparison and analysis of different cases among the countries. Another problem related to timing is that the Education Basic Law of Japan, revised on December 16, 2006, fails fully to reflect the process of policy implementation.

Lastly, the present NHRD plans were themselves formulated, implemented, and evaluated quite recently, thus making it difficult to review the latest cases by comparing them with those of the past. Once national human development plans have been completely implemented and, as a result, data and statistics have been collected, it will be possible to conduct entirely new studies that will have new significance.

\section{REFERENCES}

Gunn, L. (1978). Why is implementation so difficult? In Management Services in Government.

Kang, I., E. Lee, \& S. Kim. (2005). Analysis of Human Development Plans and Infrastructure in Northeast Asia and the Study on the Direction of Community Formation. Economic and Social Development Institute.

Mazmanian. D., \& P. Sabatier. (1983). Implementation and Public Policy.

Rein, M., \& Rabinovitz. (1978). Implementation: A theoretical perspective. In Walter Dean Burnham and Martha W. Weinberg (Eds.), American Politics and Public Policy. Cambridge, MA : MIT Press.

U.S. Department of Education. (2002). U.S. Department of Education Strategic Plan, 2002-2007. Washington, DC: U.S. Department of Education. 